\title{
RESENHA
}

\section{CULTURAS E HISTÓRIA DA EDUCAÇÃO: CONTRIBUTOS DO PROFESSOR LÚCIO KREUTZ}

\section{Cultures and history of education: contributions of professor Lúcio Kreutz}

\author{
Jordana Wruck Timm \\ Pontifícia Universidade Católica do Rio Grande do Sul, Brasil. \\ Milena Aragão \\ Universidade Federal de Sergipe, Brasil.
}

\begin{abstract}
$\cos 80$
LUCHESE, Terciane Ângela (org.). Horizontes: no diálogo entre culturas e história da educação. Caxias do Sul: UCS, 2012.
\end{abstract}

\footnotetext{
A obra Horizontes: no diálogo entre culturas e história da educação, organizada pela professora Terciane Ângela Luchese, visa a prestar homenagem a um pesquisador que muito contribuiu para as investigações na área da História e da História da Educação no Brasil: o professor Lúcio Kreutz.

Conforme Luchese (2012), este livro

nasce permeado pelo desejo de reconhecer, pela ação da palavra escrita e partilhamento de resultados de pesquisas, uma homenagem. Pela materialidade desse livro queremos reconhecer as contribuições intelectuais e humanas que o Prof. Lúcio Kreutz tem produzido ao longo de anos de trabalho como docente, pesquisador e orientador na pósgraduação em educação. (p. 13)
} 
O livro foi organizado em duas partes: a primeira, composta por nove capítulos, denomina-se Histórias da educação, e a segunda, Culturas e educação, conta com cinco capítulos.

O prefácio foi elaborado pelo professor Luciano Mendes de Faria Filho, que lembrou seu primeiro contato com os textos do professor Lúcio Kreutz, bem como relatou o momento em que teve a oportunidade de conhecê-lo pessoalmente: "era minha bibliografia em carne e osso!" (Faria Filho, 2012, p. 9).

Após o prefácio, Terciane Ângela Luchese fez a apresentação do livro, na qual assinala o momento em que conheceu o professor Lúcio Kreutz, a intenção de homenageá-lo com o livro e a escolha dos autores dos capítulos, os quais foram exorientandos, colegas pesquisadores e amigos de Kreutz.

O livro é composto de artigos escritos por diferentes autores e, por esse motivo, em se tratando do método, da teoria ou mesmo da temática empregados nas pesquisas, eles não se apresentam como uma unidade, já que as investigações foram produzidas por pesquisadores distintos, tendo focos diferentes, no entanto, unidos pelo viés da história e cultura da educação.

Nas linhas que seguem, faremos uma breve apresentação dos capítulos que compõe o livro.

\section{Histórias da educação}

O primeiro capítulo, de autoria de Elomar Antônio Callegaro Tambara, intitulado $A$ contribuição do prof. Lúcio Kreutz à pesquisa em História da Educação no Sul do Brasil, buscou analisar as produções intelectuais do professor Lúcio no campo da História da Educação. O autor escreve sobre a densidade e a importância do trabalho desenvolvido por Kreutz e das possíveis lacunas ou ensejos que suas produções deixaram e ofereceram para que novas pesquisas surgissem desse viés.

La redención de los parias: la Federación Agraria Argentina y la educación del colono en el campo argentino é o título dado ao segundo capítulo, escrito por Adrián Ascolani, no qual utiliza o jornal diário $A$ Terra, órgão oficial da Federação Agrária Argentina - FAA - como fonte de análise para pesquisar sobre petições e propostas educacionais dos agricultores da FAA.

No terceiro capítulo foram analisados o manual $O$ método facílimo para aprender a ler (1836) e O manual encyclopedico (1838), ambos escritos por Emílio Achilles Monteverde. Para quem tinha a pretensão de concluir a escola primária no século 19, esses foram os manuais mais utilizados nas escolas primárias portuguesas, além de terem sido usados no Brasil. O autor responsável pela análise dos dois manuais em questão foi António Gomes Ferreira, o qual nomeou seu texto de $A$ compreensão do sucesso de dois manuais de Emílio Monteverde para o ensino primário.

A importância do rádio como forma de divulgar propostas de modernização e pedagogia no meio rural foi tema do quarto capítulo, de autoria de Flávia Obino Corrêa Werle, intitulado Radiofonia e a formação do professor rural. O texto foi construído a partir de documentos encontrados em arquivos escolares e em entrevistas realizadas com antigos alunos e professores, levando em consideração, principalmente, as décadas de 1940 e 1960. 
O quinto capítulo traz a pesquisa desenvolvida por Beatriz T. Daudt Fischer no âmbito das fotografias como lembrança escolar. Seu texto foi denominado Recordação escolar: aluno, livros, mapa e globo: uma imagem recorrente da cultura escolar (19492004). Sua proposta investigativa buscou responder as seguintes questões: seria possível localizar antigos fotógrafos envolvidos com tais empreendimentos? Em que medida se mantém basicamente o mesmo cenário e a mesma postura de estudante nesse protótipo? Seria possível encontrar esse mesmo tipo de retrato escolar em outros contextos e épocas? Possivelmente alguns leitores devem ter uma fotografia nesses moldes (aluno, livros, mapa e globo) guardada em seu acervo fotográfico!

O sexto capítulo é de autoria de Luciane Sgarbi S. Grazziotin, intitulado Memórias de escolarização: as punições e os castigos nas escolas étnicas da Região Colonial Italiana do Rio Grande do Sul - (1896-1928), no qual a pesquisadora trabalha com entrevistas do acervo de memória oral do Ecirs/UCS, enfatizando nos relatos de professores e alunos, os castigos físicos e morais de seus tempos de escola.

No sétimo capítulo, o professor Jayme Paviani escreve um ensaio sobre a linha evolutiva, os problemas e as funções do ensino superior no contexto de uma região. $O$ texto recebeu como título O início do ensino superior em Caxias do Sul.

O oitavo capítulo trata da colonização alemã no Sul do Brasil, sendo denominado Alemães e seus descendentes no Rio Grande do Sul: entre o imperialismo alemão e o nativismo brasileiro", de Jorge Luiz da Cunha, no qual é examinada a política emigratória pangermanista alemã em relação ao Sul do Brasil, compreendendo o período entre 1980 e 1914.

O nono e último capítulo da primeira parte é de Carmem Maria Faggion e Terciane Ângela Luchese, denominado Narrativas de uma adesão: memórias escolares na região colonial italiana, RS (1930-1950). Neles as autoras escreveram sobre as experiências escolares contidas nas narrativas de alunos e professores no período em que foi desenvolvida a campanha de nacionalização.

\section{Culturas e educação}

Maria Elisabeth Blanck Miguel é autora do décimo capítulo, intitulado Relações entre educação e cultura na educação paranaense (1854-1889), no qual investiga a relação entre o professor e seu papel como elo entre educação e cultura. O público alvo de sua pesquisa são alemães católicos, imigrantes inseridos no projeto de Restauração Católica.

No décimo primeiro capítulo, Comparando vivências educacionais em diferentes contextos sócio, políticos-culturais, Zeila de Brito Fabri Demartini traça um paralelo entre os contextos africano, português e brasileiro em relação às experiências educacionais dos indivíduos em cada espaço.

O décimo segundo capítulo, intitulado Os conceitos de multiculturalismo, interculturalidade e hibridismo: conceitos que contribuem para desconstruir a história e o currículo etnocêntrico, escrito por José Licínio Backes, tematiza os três conceitos colocados em evidência no título. Para tanto, partiu dos seguintes questionamentos: esses conceitos estão contribuindo para a desconstrução da história e do currículo etnocêntrico? Como estão sendo utilizados? Há preocupação em definir esses conceitos? Eles são usados de modo diferentes? Essas diferenças são explicitadas? 
O ethos de uma educação humanizadora: reflexões sobre educação, ética e cultura contemporânea é o título do décimo terceiro capítulo do livro em questão, escrito por Danilo Romeu Streck, o qual questiona sobre o ethos e a educação humanizadora nos dias atuais, partindo da seguinte reflexão: O que seria, hoje, um ethos para a educação humanizadora?

No décimo quarto capítulo, escrito por Arthur Blásio Rambo, intitulado Conhecimento como síntese, o leitor é convidado a uma reflexão sobre o conceito de conhecimento em seus diversos desdobramentos.

O posfácio é resultado de uma entrevista realizada por e-mail com o professor Lúcio Kreutz, na qual são abordados temas relacionados à sua escolha pela história da educação; sobre leituras e professores que the serviram de base para a sua formação; interesse por pesquisas em que entrelaça etnia, imigração, cultura e educação; suas primeiras publicações e os caminhos de pesquisa; sua participação na organização de associações, como a Asphe e a SBHE, e sobre sua pesquisa atual.

Conforme Luchese (2012, p. 18) "os textos contidos neste livro, além de homenagearem o conjunto da obra intelectual de Lúcio Kreutz, sejam inspiradores para novos estudos, debates e posturas, mediante o mundo em que vivemos".

Para Faria Filho (2012),

este livro é uma homenagem e um reconhecimento ao trabalho que Lúcio vem realizando na História da Educação brasileira. Mas também é uma demonstração da fertilidade de sua produção e uma advertência ao próprio leitor: não deixe de ler os textos do Lúcio! Para nós que temos a sorte de conviver com ele, este livro é, também, uma homenagem ao modo de Lúcio ser-estar no mundo: honesto, generoso, companheiro, desafiador. Assim, ele se fez, também, grande pesquisador e professor! (Faria Filho, 2012, p. 11)

Optamos por essa citação por ela sintetizar a nossa escolha em resenhar este livro, já que como eternas orientandas do professor Lúcio, foi possível presenciar o modo como ele conduz, sabiamente, as aulas e orientações; além de ter a satisfação de conviver com o seu modo de ser-estar, com sua honestidade, generosidade, companheirismo e constantes momentos em que nos desafia a ir mais longe, de buscar mais, de evoluir:

E, quando perguntado sobre como gostaria de ser lembrado, Lúcio responde: 'Apenas gostaria de ser lembrado como um cara que foi esforçado, transparente, bom e feliz. Considero-me abençoado por Deus'. (2012, por e-mail). É assim, de modo simples, sem as vaidades tão comuns no mundo acadêmico, que Lúcio Kreutz se constituiu como referência aos que estudam temáticas que vinculam história da educação, etnia, cultura, processos identitários, escola de imigrantes, nacionalização e diversidade cultural, entre outros. (Luchese, 2012, p. 15)

Indubitavelmente, o professor Lúcio Kreutz é reconhecido como um sujeito esforçado, transparente, bom e feliz, mas sua modéstia não lhe deixa transparecer tudo o mais que ele é: um orientador, um pesquisador e profissional de renome e reconhecido por suas produções, e muito mais que as palavras aqui não conseguiriam expressar. 
Salientamos a importância desse livro para a história da educação, no sentido da produção intelectual, bem como de conhecer um pouco mais dessa pessoa de tanto brilho. Tal como Faria Filho recomendou no prefácio, não deixe de ler os textos do Lúcio, e, também, não deixe de ler este livro.

JORDANA WRUCK TIMM é estudante do curso de doutorado em Educação na Pontifícia Universidade Católica do Rio Grande do Sul. É mestre em Educação, psicopedagoga, pedagoga e bolsista da Capes.

Endereço: Avenida Marechal Floriano Peixoto, 3072 - 96170-000 - São Lourenço do Sul - RS - Brasil.

E-mail: jordanawruck@hotmail.com.

MILENA ARAGÃo é estudante do curso de doutorado em Educação na Universidade Federal de Sergipe. É mestre em Educação, psicóloga e bolsista da Fapitec/SE.

Endereço: Rua Jornalista Paulo Costa, 577 - 49037-340 - Aracaju - SE - Brasil.

E-mail: mi.aragao@yahoo.com.br.

Recebido em 6 de dezembro de 2013.

Aceito em 10 de maio de 2014. 